Brazilian Journal

of Chemical

Engineering

\title{
OPTIMIZATION OF HIGH-CONCENTRATION TRANS-ANETHOLE PRODUCTION THROUGH HYDRODISTILLATION OF STAR ANISE
}

\author{
Bárbara G. I. Destro ${ }^{1}$, Regina M. M. Jorge ${ }^{1}$ and Alvaro L. Mathias ${ }^{1 *}$ \\ ${ }^{1}$ Universidade Federal do Paraná, Departamento de Engenharia Química, Programa de Pós-Graduação em Engenharia de Alimentos, \\ Curitiba, PR, Brasil. E-mail: mathias@ufpr.br - ORCID: 0000-0003-2536-4516
}

(Submitted: May 15, 2018 ; Revised: August 13, 2018 ; Accepted: September 18, 2018)

\begin{abstract}
Illicium verum Hook essential oil (EO) is composed mainly of trans-anethole (TA), which has therapeutic potential. The extraction is usually by hydrodistillation, taking long hours, leaving the process costly and product with lower quality. Thus, the present study sought to optimize dehydrated fruit fragmentation by BoxWilson central composite design and EO extraction and EO quality using a $2^{4-1}$ fractional factorial design. It is concluded that the fruits must be fragmented to sizes smaller than $425 \mu \mathrm{m}$ using a knife mill. For hydrodistillation, the condition reported as ideal was granulometry $<0.425 \mathrm{~mm}, 8 \%$ mass, 1 hour and water volume of $200 \mathrm{~mL}$. This process provided an EO yield of $10.2 \%$ and high-grade TA (96.6\%), requiring shorter time of extraction. Keywords: Antioxidant; Essential oil; Hydrodistillation; Illicium.
\end{abstract}

\section{INTRODUCTION}

Star anise (Illicium verum Hook) is an aromatic vegetable cultivated in Asian countries, especially in China and Vietnam (Asif et al., 2016; Wang et al. 2007). Its fruit contains volatile oil, resin, fat, tannin, pectin, and mucilage, whereas its seeds contain little volatile oil, resin, and a large amount of non-volatile oil (Chempakam \& Balaji, 2008; Li et al., 2010; Wang et al., 2011). Its aroma is due especially to its high essential oil content, $2.5-3.5 \%(\mathrm{w} / \mathrm{w})$ in fresh fruit and $8-9 \%$ in dried fruit (Wang et al., 2007). The essential oil, which is found in the pericarp but not in the seed, consists mainly of trans-anethole: $70-94 \%$ (Asif et al., 2016; Bhadra et al., 2011; Chouksey, Upmanyu, \& Pawar, 2013; Wang et al., 2007). This active compound molecular formula, weight, and CAS Number are $\mathrm{C}_{10} \mathrm{H}_{12} \mathrm{O}, 148.205$ g.mol ${ }^{-1}$ and 4180-23-8, respectively (PubChem, 2005). Trans-anethole has been increasingly studied for its antioxidant properties (Wong, Lee, \& Nurdiyana, 2014), anticancer properties (Asif et al., 2016) and for its potential use in treating neurodegenerative diseases (Bhadra et al., 2011). The star anise essential oil (EO) may also contain estragole (Howes, Kite \& Simmonds, 2009), D-limonene (Chouksey et al., 2013), cis-anethole (Wang et al., 2007; Wang et al., 2011), pinene, $\beta$-phellandrene, safrol, farnesol and $\alpha$-terpineol (Chouksey et al., 2013).

For EO extraction, hydrodistillation is the method most commonly employed. However, yields which vary from $4 \%(\mathrm{v} / \mathrm{w})$ (Bhadra et al., 2011) to $8.2 \%$ (Wang et al., 2007) have been reported in the literature, also needing a long process time, from $2 \mathrm{~h}$ (Bhadra et al., 2011) to $5 \mathrm{~h}$ (Wang et al., 2007).

The goal of this study is to optimize the extraction of this essential oil from dehydrated star anise fruit, as well as to determine its quality in terms of transanethole content.

\section{MATERIALS AND METHODS}

Dehydrated star anise fruit from the edible species Illicium verum Hook, imported from China and commercialized in the Municipal Market of Curitiba, PR, Brazil, was stored under refrigeration after being

\footnotetext{
* Corresponding author: Alvaro L. Mathias - E-mail: mathias@ufpr.br
} 
homogenized and quartered to guarantee reliability, especially in terms of its initial granulometry. The granulometric distribution of $100 \mathrm{~g}$ of each sample was measured in triplicate after $10 \mathrm{~min}$ of agitation in sieves with mesh sizes of $8,9,12,14,20,28,35$, 48 and $100\left(\right.$ BERTEL $\left.^{\circledR}\right)$. Pre-fragmentation has been reported to increase oil yield from the hydrodistillation process (Cai et al., 2014; Li et al., 2010), and it was carried out by using a domestic blender (Clic'Lav, $\left.\mathrm{ARNO}^{\circledR}\right)$. The initial moisture content of the fruit that had been previously ground (WHO, 2011) in a blender (20 g for $20 \mathrm{~s}$ ), was determined in triplicate by oven-drying at $105^{\circ} \mathrm{C}$ (AOAC, 2000; Shreve, Thiex, $\&$ Wolf, 2006). An alternative method using infrared drying was also applied in triplicate using System BG200 (GEHAKA ${ }^{\circledR}$ ) at $60^{\circ} \mathrm{C}$ and $105^{\circ} \mathrm{C}$ until constant mass (approximately $15 \mathrm{~min}$ ). The water activity was evaluated using Aqualab Pre (DECAGON®), also in triplicate.

For the grinding studies, the effect of time ( $\mathrm{t}$ ) and mass (m) were evaluated in duplicate by means of a Box-Wilson central composite design (Table 1).

For preliminarly essential oil extraction tests, dried fruits $(50 \mathrm{~g})$, both ground (in a knife mill, $20 \mathrm{~g}$ of sample for $20 \mathrm{~s}$ on high power) and whole, were combined with distilled water $(500 \mathrm{~mL})$ and heated in a Clevenger apparatus for 180 min using a QUIMIS ${ }^{\circledR}$ heating mantle (Q-321A25, $315 \mathrm{~W})$. After cooling, the oil was centrifuged $(10,000 \mathrm{rpm}$ at $5 \mathrm{~min}=14,257$ $\mathrm{xg}$ at $5 \mathrm{~min})$ in a THERMO SCIENTIFIC ${ }^{\circledR}$ Centrifuge (Heraeus Fresco 21) in microtubes (1.5 mL). The lipidic phase was tranfered to another set of microtubes containing approximately $7 \%(\mathrm{~m} / \mathrm{v})$ anhydrous sodium

Table 1. Grinding tests for star anise fruit.

\begin{tabular}{ccc}
\hline No. & $\mathbf{t}(\mathbf{s})$ & $\mathbf{m} \mathbf{( g )}$ \\
\hline G1 & $10(-1)$ & $10.00(-1)$ \\
G2 & $10(-1)$ & $20.00(+1)$ \\
G3 & $20(+1)$ & $10.00(-1)$ \\
G4 & $20(+1)$ & $20.00(+1)$ \\
G5 & $8^{2}(-1.41)$ & $15.00(0)$ \\
G6 & $22^{2}(+1.41)$ & $15.00(0)$ \\
G7 & $15(0)$ & $7.93(-1.41)$ \\
G8 & $15(0)$ & $22.07(+1.41)$ \\
G C (i) & $15(0)$ & $15.00(0)$ \\
\hline${ }^{1}$ Center points in duplicates, $i=1-2{ }^{2}$ Approximately &
\end{tabular}

sulfate (CAS 7757-82-6, ANALYTICALS ${ }^{\circledR}$ ). This salt is commonly used as an oil drying agent (Zhai et al., 2009). The dehydrated oils were subsequently stored under refrigeration $\left(4 \pm 1^{\circ} \mathrm{C}\right)$ (Bhadra et al., 2011; Chempakam \& Balaji, 2008; Wang et al., 2007), and after stabilization (overnight), another centrifugation was carried out under the same conditions. The dried essential oil was hermetically conditioned in amber vials and stored under refrigeration. As an alternative method, a classical Soxhlet extraction was performed in duplicate using ethyl ether (CAS number 60-29-7, $\left.\mathrm{NUCLEAR}^{\circledR}\right)$ to extract the lipid fraction from $8 \mathrm{~g}$ of each sample (crushed and whole) contained in filter paper Qualy $15.0 \varnothing\left(\mathrm{J}\right.$. PROLAB $\left.{ }^{\circledR}\right)$ and capped with cotton for $5 \mathrm{~h}$ at $85^{\circ} \mathrm{C}$. Lipid fraction yield was determined after the solvent had evaporated for $60 \mathrm{~min}$ at $100^{\circ} \mathrm{C}$. The oil extracted by the Soxhlet method received the same treatment and storage described above.

The effect of the granulometry, mass of the dried fruit, extraction time, and the water volume on the yield of star anise essential oil (EO) extracted by hydrodistillation was assessed using a $2^{4-1}$ fractional factorial design (Table 2). The levels were established according to previous research and preliminary tests.

For granulometry, a small particle size, ideally between $0.25 \mathrm{~mm}$ (60 mesh) and $0.425 \mathrm{~mm}$ (40 mesh) has been reported to result in higher star anise EO yields (Cai et al., 2014; Li et al., 2010). Therefore, it was decided to work with $0.43 \mathrm{~mm}$ bands for the present study.

Masses between 8 and 16\% (m/v) were used (Wang et al., 2007; Zhai et al., 2009). Regarding extraction time, preliminary tests indicated stabilization of the volume of essential oil obtained after 3 hours (data not shown). The volume of distilled water varied from $200 \mathrm{~mL}$ (minimum quantity required to fill in the system), to $500 \mathrm{~mL}$ (maximum for safe operation). The refractive index was measured using an Abbe refractometer (BIOBRIX $\AA)$ at $25^{\circ} \mathrm{C}$ (Garber, Herrlinger, \& Ciesielslsi, 1962; Tuan \& Ilangantileket, 1997). The response variables were yield on a dry basis $\left(\mathrm{Y}_{\mathrm{DB}}\right.$, in $\mathrm{g} \mathrm{EO} / 100 \mathrm{~g}$ dry matter) and trans-anethole content (TA, \%).

The moisture of the EOs and the TA standard (CAS 4180-23-8, EASTMAN CHEMICAL COMPANY ${ }^{\circledR}$ )

Table 2. Hydrodistillation conditions for star anise essential oil extraction.

\begin{tabular}{ccccc}
\hline Tests & $\mathbf{G}(\mathbf{m m})$ & $\mathbf{m} \mathbf{( \% )}$ & $\mathbf{t}(\mathbf{h})$ & $\mathbf{V}(\mathbf{m L})$ \\
\hline HD1 & $<0.43(-1)$ & $8(-1)$ & $1(-1)$ & $200(-1)$ \\
HD2 & $>0.85(+1)$ & $8(-1)$ & $1(-1)$ & $500(+1)$ \\
HD3 & $<0.43(-1)$ & $16(+1)$ & $1(-1)$ & $500(+1)$ \\
HD4 & $>0.85(+1)$ & $16(+1)$ & $1(-1)$ & $200(-1)$ \\
HD5 & $<0.43(-1)$ & $8(-1)$ & $3(+1)$ & $500(+1)$ \\
HD6 & $>0.85(+1)$ & $8(-1)$ & $3(+1)$ & $200(-1)$ \\
HD7 & $<0.43(-1)$ & $16(+1)$ & $3(+1)$ & $200(-1)$ \\
HD8 & $>0.85(+1)$ & $16(+1)$ & $3(+1)$ & $500(+1)$ \\
HD C (i) ${ }^{1}$ & $0.43<\mathrm{G}<0.85(0)$ & $12(0)$ & $2(0)$ & $350(0)$ \\
\hline
\end{tabular}

${ }^{1}$ Center points in triplicate, $\mathrm{i}=1-3$. 
was assessed according to the official methodology of the Karl Fischer method (AOAC, 2000). Thermogravimetric analysis (TGA) was performed on $10 \mu \mathrm{L}$ of EO or TA standard in platinum crucibles (200 $\mu \mathrm{L})$ in a TGA 4000 (PERKIN ELMER ${ }^{\circledR}$ ) in a high purity nitrogen atmosphere $(50 \mathrm{~mL} / \mathrm{min})$ from 30 to $410^{\circ} \mathrm{C}$ at a $10^{\circ} \mathrm{C} / \mathrm{min}$ heating rate. Gas Chromatography-Mass Spectrometry (GC-MS; GC-2010 Plus, SHIMADZU ${ }^{\circledR}$, Japan) was conducted based on Bhadra et al. (2011) employing a capillary column DB5 $(30 \mathrm{~m}$ x $0.32 \mathrm{~mm}$, $0.25 \mu \mathrm{m}$ film thickness, J\&W Scientific Inc., Folsom, CA, U.S.A.) with cross-linked $5 \%$ phenylmethylsilicone. The mobile phase was also Helium gas, but at a flow rate of $1.2 \mathrm{ml} / \mathrm{min}$. The oven temperature was isothermal at $40{ }^{\circ} \mathrm{C}$ for $5 \mathrm{~min}$, then increased at $5{ }^{\circ} \mathrm{C} /$ min until $220^{\circ} \mathrm{C}$. It was kept isothermal for 10 $\min$. For the injection, the temperature was $220^{\circ} \mathrm{C}$, and for the interface, $200{ }^{\circ} \mathrm{C}$. In the present study the injection volume used was $1.0 \mu \mathrm{L}$ with a split ratio of 1:20. TA in EOs was identified by mass spectral data from the NIST/EPA/NIH virtual library and quantified using the areas and the standard curve. The EO quality obtained by regrinding the previous residue $(20 \mathrm{~g}$ for $20 \mathrm{~s})$ was assessed. After each milling, the fraction lower than $0.40 \mathrm{~mm}$ was removed. The material (16 g) was hydrodistilled under condition HD1 (Table 2) of the optimization. $\mathrm{Y}_{\mathrm{DB}}(\mathrm{g} \mathrm{EO} / \mathrm{g} \mathrm{dm})$, TA content (\%) and the yield purity $\left(\mathrm{Y}_{\mathrm{DB}} / \mathrm{TA}\right)$ of the $\mathrm{EO}$ were also analyzed for these oils.

The experimental design was implemented in STATISTICA $7^{\circledR}$ (StatSoft, Inc.). ANOVA and Tukey univariate analyses were applied in the Action Stat (Estat Camp) supplement from Excel $^{\circledR}$ (Microsoft Corporation). A 95\% significance level was used.

\section{RESULTS AND DISCUSSION}

Star anise is composed of 6-8 carpels, each of which measures at least $10 \mathrm{~mm}$ (Chempakam \& Balaji, 2008; Wang et al., 2011). In this study, more than $99.14 \%$ ( \pm $0.14 \%$ ) of the star anise fruits had particles larger than $2360 \mu \mathrm{m}$ (detailed data not shown), indicating a good integrity of the commercial samples.

A traditional drying tecnique (oven at $105^{\circ} \mathrm{C}$ ) exhibited a higer moisture content in the ground samples $(16.55 \pm 0.33 \%, \mathrm{~m} / \mathrm{m})$ than previouly reported: $8-12 \%$ (Chempakam \& Balaji, 2008), 8.59\% (Wang et al., 2007) and 14.9\% (Zhai et al., 2009). This difference can be explained by either the biological variation between the specimens or error attributed to the technique. In addition to the traditional technique, moisture was also evaluated by infrared drying as well, at 60 or $105^{\circ} \mathrm{C}$.

Although moisture results depend on the technique used (Tukey test, $\mathrm{p}>0.05$ ), low dispersions (standard deviation) were observed. The highest moisture content was observed for the drying oven at $105^{\circ} \mathrm{C}$ $(16.55 \pm 0.33 \%, \mathrm{~m} / \mathrm{m})$, followed by infrared drying at $105^{\circ} \mathrm{C}(14.63 \pm 0.33 \%, \mathrm{~m} / \mathrm{m})$ and at $60^{\circ} \mathrm{C}(12.98$ $\pm 0.14 \%, \mathrm{~m} / \mathrm{m})$; this can be attributed to the loss of other volatile materials. TG and DTG curves of the EO from crushed $(20 \mathrm{~g}, 20 \mathrm{~s})$ star anise fruits or and the TA standard (Figure 1) reinforced this hypothesis. Mass loss exhibited similar behavior for EO $(0.788 \%)$ and TA $(0.536 \%)$ between $40^{\circ} \mathrm{C}$ and $60^{\circ} \mathrm{C}$. Likewise, $13.8 \%$ of TA and $15.5 \%$ of EO were degraded from 40 to $105^{\circ} \mathrm{C}$. In other words, there is a relevant loss of EO components when higher drying temperatures are used. Therefore, the moisture evaluation should be carried out at a low temperature to avoid overestimating the water content (e.g., it should be performed at $60^{\circ} \mathrm{C}$ using the infrared method).

A moisture value of $12.98 \%$ was used for calculating the dry basis oil yield. The TA standard mass loss peak $\left(145.1^{\circ} \mathrm{C}\right)$ was very similar to that of the EO $\left(147.7^{\circ} \mathrm{C}\right)$. Residual mass was also very similar, $4.1 \%$ and $3.8 \%$, repectively: a difference of $7.3 \%$. These results suggest that the EO has a high TA content, which has been described to be around 7094\% (Chouksey et al., 2013; Herrera, 2009).

For most halophilic bacteria and mycotoxigenic asperilli development water activity is between 0.75 and 0.80 (Damodaran, Parkin, \& Fennema, 2008; Tapia, Alzamora, \& Chirife, 2007). For the ground star anise $(20 \mathrm{~g}, 20 \mathrm{~s})$, its value was $0.7853( \pm 0.0062)$. Thus, the product requires storage at low temperatures until its final consumption.

Fragmentation of fruit samples by a knife mill was simulated using a blender to maximize essential oil production. The dried star anise fruit is not an isotropic material, as suggested by the cumulative grinding curve (Figure 2, a). There are three distinct fracture susceptibility fractions, one producing a fine fraction (indicated by $\mathrm{A}$ ), another producing an intermediate fraction (B), and yet another producing a coarse

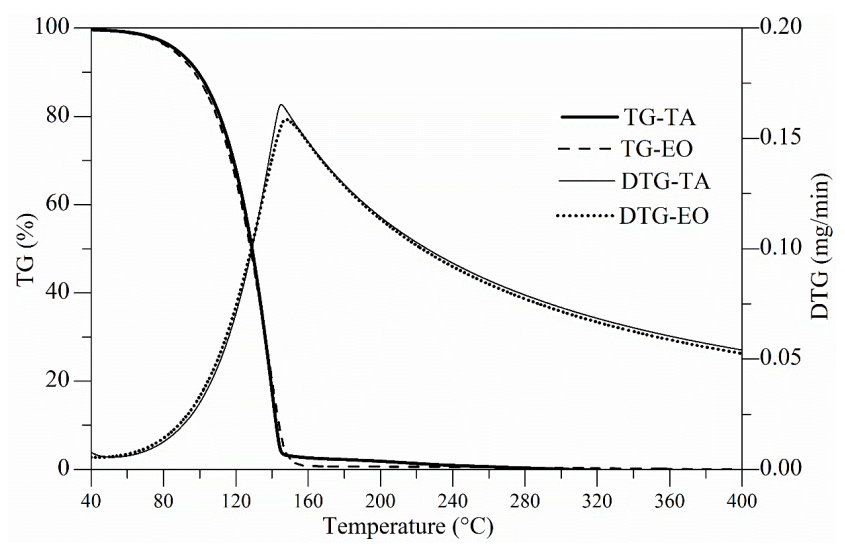

Figure 1. TG (\%) and DTG (mg/min) curves for transanethole standard (TA) and star anise essential oil (EO). 

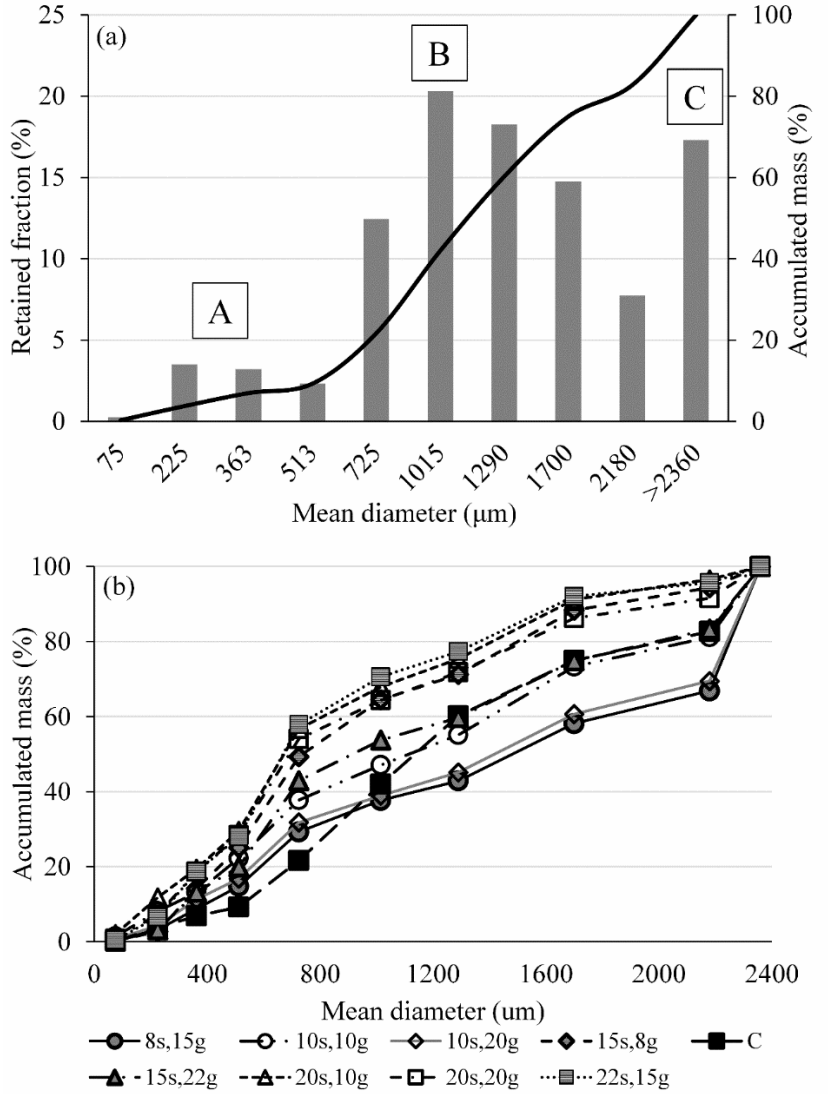

Figure 2. (a) Average profile of the fractions of commercial fruit $(15 \mathrm{~g})$ fragmentation subjected to milling (15s); (b) Effect of commercial fruit mass and time on accumulated mass on different fractions.

fraction $(\mathrm{C})$. The first may be associated with the more friable portions of the fruit, whereas the latter consists mainly of seeds (Figure 2, a). The seed is not the main source of oil (Chempakam \& Balaji, 2008; Li et al., 2010; Wang et al., 2011) therefore, it can be separated to avoid introducing unnecessary material into the hydrodestillation system. There is a significant $(p<$ 0.050 ) linear effect of both time and fruit mass and a quadratic effect of time (Table 3 ) on the accumulated mass in sieves of different sizes (Figure 2, b). Longer milling times, $20 \mathrm{~s}, 10 \mathrm{~g}$ or $22 \mathrm{~s}, 15 \mathrm{~g}$, result in larger accumulated fractions in the smaller mean diameter sieves $362.5 \mu \mathrm{m}$ (19.48\% and $18.68 \%$, respectively) and $725 \mu \mathrm{m}(56.76 \%$ and $57.87 \%$, respectively) than do shorter milling times $8 \mathrm{~s}, 15 \mathrm{~g}$ and $10 \mathrm{~s}, 20 \mathrm{~g}$. In these cases, for the same mean diameters, the values were $8.82 \%$ and $11.28 \%$, and $29.24 \%$ and $31.76 \%$, respectively. Mass distribution within $15 \mathrm{~s}$ assumes the intermediate behaviour (Figure 2, b). Such behavior was expected, since the longer the material remains in the grinding equipment, the greater the degree of fineness obtained.

Hydrodistillation is usually more efficient when smaller particles are used, especially those smaller than 60 mesh $(250 \mu \mathrm{m})$ or 40 mesh $(425 \mu \mathrm{m})$. Nevertheless, the data were plotted using three granulometry intervals $(0-425 \mu \mathrm{m}, 425-850 \mu \mathrm{m}$ and $>850 \mu \mathrm{m})$ in order to both evaluate the effects of time and mass and to understand the operation. The effect of time was easily observed (Figure 3, a), but that of mass was not (Figure 3, b). Particles smaller than $425 \mu \mathrm{m}$ were obtained (Figure 3, c), which is the recommended range for hydrodistillation (Cai et al., 2014; Li et al., 2010). Acording to ANOVA (Table 3), both parameters are statistically significant $(p<0.050)$ and the yield of retained mass ( $R, \%)$ for particles smaller than $425 \mu \mathrm{m}$ is described by Equation 1, with actual values:

$R(t, m)=0.0623 t^{2}-1.1765 t-0.0016 m^{2}+16.3733$

The condition $8 \mathrm{~s}, 15 \mathrm{~g}$ and the center point $(15 \mathrm{~s}$, $15 \mathrm{~g}$ ) (Figure 3, c) did not differ statistically between themselves (same letters do not differ significantly by Tukey's test; $p \leq 0.05$ ), but they were different from the others. At the study limits, the larger times $(20 \mathrm{~s}$ and $22 \mathrm{~s}$ ) allowed the use of a wide variation of mass to be crushed. However, the mass to be ground is time dependent (letters b, Tukey's test) with intermediate values. In general, higher milling times increased yield in the $0-425 \mu \mathrm{m}$ interval and small sample quantities appear to be favorable for the intermediate time (Figure 3, c). A standard sample amount (20 g) and a standard grinding time $(20 \mathrm{~s})$ were used in the subsequent oil extraction tests in order to reduce the heating of the samples (thus avoid the consequent loss of volatile compounds) and to avoid crushing the seeds, which according Chempakam \& Balaji (2008); Li et al. (2010) and Wang et al. (2011), are poor in trans-anethole.

Different characteristics are observed in oils obtained using different extraction techniques. Hydrodistillation of crushed fruits (Clevenger apparatus) produced an EO with a strong anise flavor, a smooth, transparent, yellowish color, and a viscous behavior at room temperature. It solidified under refrigeration. In contrast, the EO produced by the Soxhlet equipment exhibited a bitter anise flavor with a solvent odor, a dark green coloration, and lower viscosity. These same characteristics were reported by Wang et al. (2007), who produced star anise oil by hydrodistillation and Soxhlet extraction with yields of 8.2 and $9.3 \%$, respectively. In the present study, the yield was lower for hydrodistillation of whole star anise $(3.84 \pm 0.33 \mathrm{~g} \mathrm{EO} / \mathrm{g} \mathrm{dm})$ and even for the finely ground fraction of the crushed fruit $(0-0.425 \mathrm{~mm}, 6.41$ $\pm 0.50 \mathrm{~g} \mathrm{EO} / \mathrm{g} \mathrm{dm})$. However, crushing had a very important influence on Soxhlet extraction yield (1.20 $\pm 0.01 \mathrm{~g} \mathrm{EO} / \mathrm{g} \mathrm{dm}$ for the whole fruit and $13.02 \pm 1.09$ $\mathrm{g} \mathrm{EO} / \mathrm{g} \mathrm{dm}$ for the crushed fruit). The higher value can be attributed to the concentration step applied by Wang et al. (2007), which was not performed in the present 

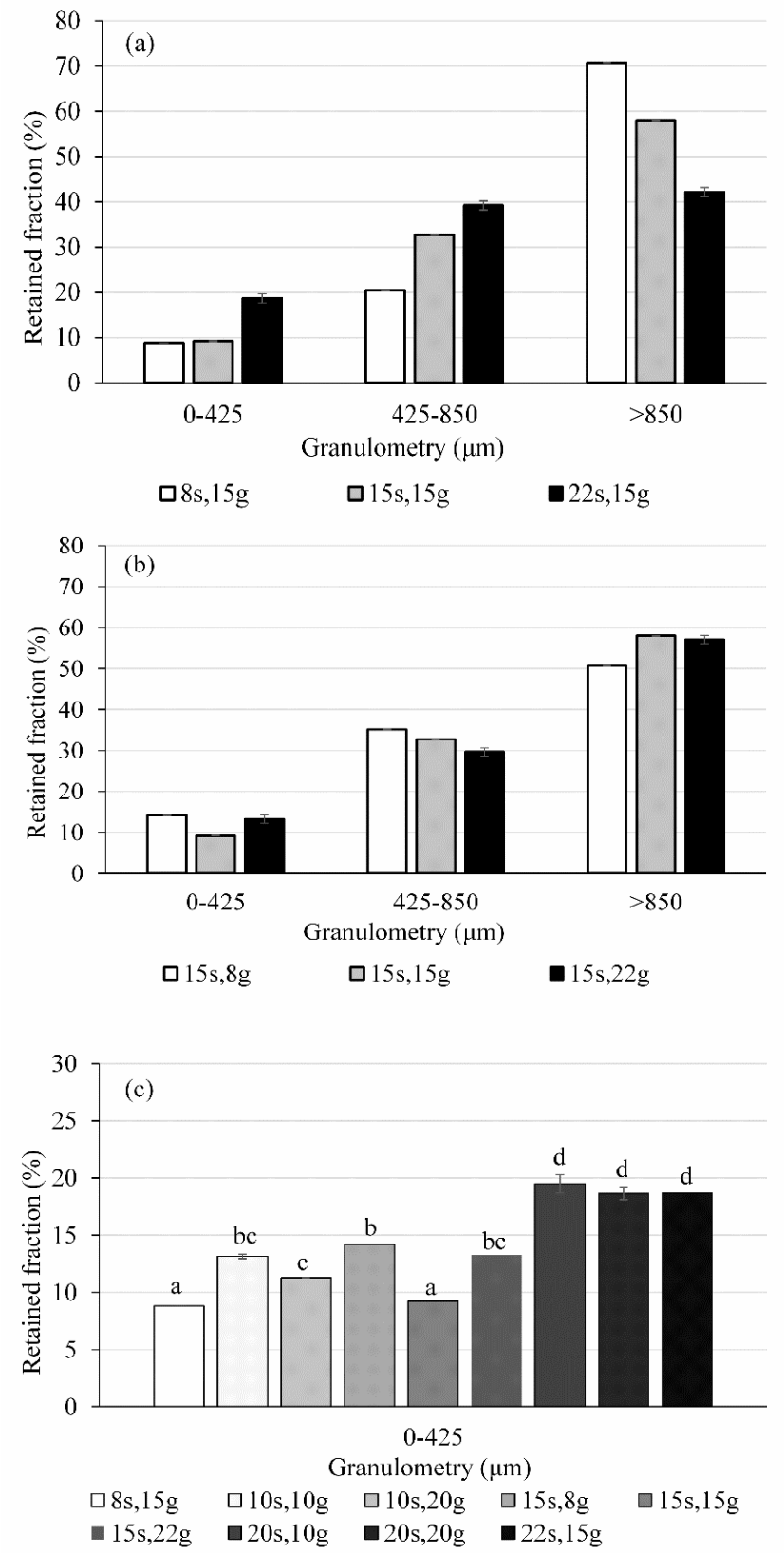

Figure 3. (a) Retained fraction (\%) for different time grinding conditions and (b) for $15 \mathrm{~s}$ and different mass; (c) Influence of star anise sample mass and milling time on the fine fraction retention $(0-425 \mu \mathrm{m})$. *Same letters do not differ significantly by Tukey's test $(\mathrm{p} \leq 0.05)$. study because the physical characteristics of the raw oil obtained would be inappropriate for ingestion (aroma, color, solvent residue).

Moisture content of star anise oil samples submitted to hydrodestillation was very low $(0.11 \pm$ $0.01 \%$ ) and similar to that of standard trans-anethole $(0.10 \pm 0.01 \%)$. Therefore, star anise granulometry, mass, time and initial water volume were investigated for the hydrodistillation technique in order to optimize yield as a function of these variables (Table 4). The highest yield (exp.7, Table 4) was observed for the highest mass ratio between dry fruit and water (16\%), the longest operating time $(3 \mathrm{~h})$ and using the finest particles $(0-0.43 \mathrm{~mm})$. This confirms the importance of reducing fruit size (Cai et al., 2014; Li et al., 2010), and increasing the ratio of fruit mass to water, which should be higher than 10\% (Chempakam \& Balaji, 2008 ), in the extraction of essential oil from the matrix. However, only the effect of the granulometry $(\mathrm{G})$ was significant $(p=0.006<0.050)$ for the yield, whereas time $(\mathrm{t})$ was marginally significant $(\mathrm{p}=0.050)$. Oil $\mathrm{Y}_{\mathrm{DB}}$ ( $\mathrm{g} \mathrm{EO} / 100 \mathrm{~g} \mathrm{dm}$ ) can be described by the following model (Equation 2), with actual values:

$\mathrm{Y}_{\mathrm{DB}}(\mathrm{G}, \mathrm{t})=-9.8960 \mathrm{G}+0.2078 \mathrm{Gt}+0.7158 \mathrm{t}+12.4852$

The highest EO yields occurred in experiments HD1, HD5 and HD7 (granulometry $\mathrm{G}<0.43 \mathrm{~mm}$ ), and are higher than the values of $4 \%$ and $8.2 \%$ previously reported by Bhadra et al. (2011) and Wang et al. (2007), respectively. A Tukey test $(\alpha=0.05)$ of the refractive index of different EOs indicates that sample HD7 exhibits a significant difference when compared to samples HD2 $(\mathrm{p}=0.044)$, HD4 $(\mathrm{p}=0.044)$, HD6 $(\mathrm{p}=0.044)$ and TA $(\mathrm{p}=0.025)$. TA differed from HD3 ( $p=0.041), \operatorname{HD} 5(\mathrm{p}=0.031)$, HD7 $(\mathrm{p}=0.025)$, and HD C (i) $(p=0.034)$. The parameter was sligthly lower than for standard TA (1.5565) and data reported by other authors for star anise EO: 1.5553 (Tuan \& Ilangantileket, 1997) and 1.5585 (Garber et al., 1962) both at $25^{\circ} \mathrm{C}$.

Trans-anethole (TA) was the main component quantified in star anise essential oil by GC-MS analysis (Figure 4), in agreement with what has been described in previous studies (Asif et al., 2016; Bhadra

Table 3. Analysis of variance (ANOVA) and effect of time and mass on grinding in order to obtain a fine fraction $(<425 \mu \mathrm{m})$.

\begin{tabular}{|c|c|c|c|c|c|c|}
\hline Factor & SS & df & MS & $\mathbf{F}$ & p & Effect \\
\hline (1) t (L) & 95.6097 & 1 & 95.60974 & 50.71629 & $0.002055^{*}$ & $+6.9141 *$ \\
\hline $\mathrm{t}(\mathrm{Q})$ & 34.2640 & 1 & 34.26405 & 18.17540 & $0.013020 *$ & $+5.4755^{*}$ \\
\hline (2) m (L) & 2.0118 & 1 & 2.01179 & 1.06715 & 0.359953 & -1.0029 \\
\hline $\mathrm{m}(\mathrm{Q})$ & 33.7253 & 1 & 33.72529 & 17.88962 & $0.013374 *$ & $-1.0330 *$ \\
\hline $1 \mathrm{~L}$ by $2 \mathrm{~L}$ & 0.2644 & 1 & 0.26437 & 0.14023 & 0.727057 & +5.4323 \\
\hline Error & 7.5408 & 4 & 1.88519 & & & 0.5142 \\
\hline Total SS & 153.0203 & 9 & & & & \\
\hline
\end{tabular}

* Statistically significant $(\mathrm{p}<0.05)$. 
Table 4. Optimization of EO extraction and selectivity for trans-anethole yield.

\begin{tabular}{ccccccccc}
\hline Exp. & $\begin{array}{c}\mathbf{G} \\
(\mathbf{m m})\end{array}$ & $\begin{array}{c}\mathbf{m} \\
(\mathbf{\%})\end{array}$ & $\begin{array}{c}\mathbf{t} \\
\mathbf{( h )}\end{array}$ & $\begin{array}{c}\mathbf{V} \\
(\mathbf{m L})\end{array}$ & $\begin{array}{c}\text { Refractive } \\
\mathbf{I n d e x}\end{array}$ & $\begin{array}{c}\mathbf{Y}_{\text {DB }} \\
(\mathbf{g ~ E O} / \mathbf{1 0 0} \mathbf{g} \mathbf{d m})\end{array}$ & $\begin{array}{c}\text { TA } \\
\mathbf{( \% )}\end{array}$ & $\begin{array}{c}\mathbf{Y}_{\mathbf{D B} \text { TA }} \\
(\mathbf{g ~ T A} / \mathbf{1 0 0} \mathbf{g} \mathbf{d m})\end{array}$ \\
\hline HD1 & $<0.43$ & 8 & 1 & 200 & 1.5545 & 10.2 & 96.6 & 9.85 \\
HD2 & $>0.85$ & 8 & 1 & 500 & 1.5555 & 5.4 & 82.2 & 4.44 \\
HD3 & $<0.43$ & 16 & 1 & 500 & 1.5534 & 8.0 & 85.5 & 6.84 \\
HD4 & $>0.85$ & 16 & 1 & 200 & 1.5555 & 5.1 & 85.9 & 4.38 \\
HD5 & $<0.43$ & 8 & 3 & 500 & 1.5529 & 10.6 & 82.2 & 8.71 \\
HD6 & $>0.85$ & 8 & 3 & 200 & 1.5555 & 6.7 & 81.3 & 5.45 \\
HD7 & $<0.43$ & 16 & 3 & 200 & 1.5525 & 10.8 & 80.4 & 8.68 \\
HD8 & $>0.85$ & 16 & 3 & 500 & 1.5539 & 7.3 & 80.8 & 5.90 \\
HD C (1) & $0.43<\mathrm{G}<0.85$ & 12 & 2 & 350 & 1.5537 & 8.9 & 80.0 & 7.09 \\
HD C (2) & $0.43<\mathrm{G}<0.85$ & 12 & 2 & 350 & 1.5539 & 8.9 & 78.7 & 6.99 \\
HD C (3) & $0.43<\mathrm{G}<0.85$ & 12 & 2 & 350 & 1.5535 & 8.9 & 79.4 & 7.03 \\
\hline
\end{tabular}

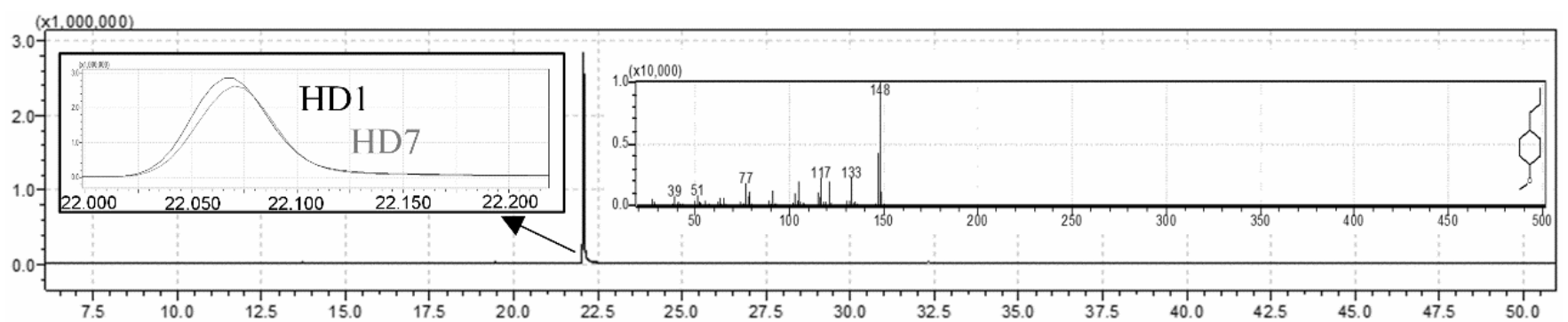

Figure 4. Gas chromatogram of the essential oil in hydrodistillation conditions one (HD1) and seven (HD7). In the zoom, on the left: HD1 and HD7. On the right: EO MS spectra.

et al., 2011; Chouksey et al., 2013; Howes, Kite \& Simmonds, 2009; Wang et al., 2007; Zhai et al., 2009). The inset zoom (Figure 4) emphasizes conditions one (HD1) and seven (HD7) of hydrodistillation, since they yielded higher TA content and oil mass, respectively. In the present study traces were also identified of two compounds reported by many other authors: estragole (Chouksey et al., 2013; Howes, Kite \& Simmonds, 2009; Wang et al., 2011; Wong et al., 2014) and D-limonene (Chouksey et al., 2013; Zhai et al., 2009). Foeniculin, another substance which has been reported in the edible species of star anise (e.g., I. verum) (Chouksey et al., 2013; Howes, Kite \& Simmonds, 2009) was also found. The presence of this substance indicates that the samples used in the present study are edible, because toxic species (e.g., I. anisatum) do not contain this molecule (Howes, Kite $\&$ Simmonds, 2009). Pinene, $\beta$-phellandrene, safrol, farnesol and $\alpha$-terpineol were not identified (Chouksey et al., 2013).

For TA (\%) purposes (Table 4), an ANOVA test for the studied parameters indicated no significant effects $(\mathrm{p}<0.050)$, but HD1 exhibited the highest TA grade $(96.6 \%)$.

The yield purity $\left(\mathrm{Y}_{\mathrm{DB}} / \mathrm{TA}\right)$ of the EO was highly affected by granulometry $(p=0.0002)$, thus confirming its dependence on the anisotropic portion of the vegetable. Time $(\mathrm{t}, \mathrm{p}=0.017)$, mass $(\mathrm{m}, \mathrm{p}=0.030)$ and volume $(\mathrm{V}, \mathrm{p}=0.033)$ are statiscally significant $(p<0.050)$, but lower than the linear interactions GV $(\mathrm{p}=0.013)$ and $\mathrm{Gm}(\mathrm{p}=0.014)$, which appear to be marginally significant. Therefore, although condition HD7 exhibited a higher EO yield, the best conditions for obtaining an oil rich in TA are those of experiment HD1: a size smaller than $0.43 \mathrm{~mm}, 8 \%$ dried crushed fruit, $200 \mathrm{~mL}$ water, and $1 \mathrm{~h}$ extraction time. It is assumed that a longer extraction time promotes greater degradation of the bioactive compound of interest.

A successive milling $(\mathrm{Mi}, \mathrm{i}=1-5)$ operation (Table 5), with fractions designed to undergo hydrodistillation according to condition HD1 (Table 2), affects the EO yield and TA.

According to a Tukey test $(\alpha=5 \%)$, the first grinding differed from the other crushing in these two parameters, generating an oil with a higher grade of purity with reference to the compound of interest. There was a reduction in yield $(\mathrm{g} \mathrm{EO} / \mathrm{g} \mathrm{dm})$, refractive index, and TA $(\%)$ when grinding was repeated, reaching 1.4 $\pm 0.6 \%, 1.5520$ and $45.5 \pm 0.9 \%$, respectively. This may prove the supposition that successive milling results not only in the crushing of the fruit, but also in the breaking up of star anise seeds, which contain little

Table 5. Characterization of EO obtained from samples submitted to different millings.

\begin{tabular}{cccc}
\hline Essay & $\begin{array}{c}\mathbf{Y}_{\mathbf{D B}} \\
(\mathbf{g ~ E O} / \mathbf{g ~ d m})^{*}\end{array}$ & $\begin{array}{c}\text { Refractive } \\
\text { Index }\end{array}$ & $\begin{array}{c}\text { TA } \\
(\mathbf{\%}))^{*}\end{array}$ \\
\hline M1 & $9.5 \pm 0.2^{\mathrm{a}}$ & 1.5539 & $96.0 \pm 0.5^{\mathrm{a}}$ \\
M2 & $5.1 \pm 0.4^{\mathrm{b}}$ & 1.5535 & $72.8 \pm 4.5^{\mathrm{b}}$ \\
M3 & $3.8 \pm 0.5^{\mathrm{bc}}$ & 1.5535 & $49.8 \pm 1.6^{\mathrm{c}}$ \\
M4 & $3.7 \pm 0.4^{\mathrm{bc}}$ & 1.5535 & $48.8 \pm 1.4^{\mathrm{c}}$ \\
M5 & $1.4 \pm 0.6^{\mathrm{c}}$ & 1.5520 & $45.5 \pm 0.9^{\mathrm{c}}$ \\
\hline
\end{tabular}

* Tukey test. Equal letters in the same column indicate no significant difference. 
volatile oil and hinder both EO yield and TA purity (Chempakam \& Balaji, 2008; Li et al., 2010; Wang et al., 2011).

\section{CONCLUSIONS}

Analysis of the moisture content of dry star anise fruit should be performed using an infrared analyzer at $60^{\circ} \mathrm{C}$ to avoid false positive results due to the loss of volatile material. The fragmentation of the dry fruit with a knife mill, used in conjunction with separation by sieving may be an efficient technique for selecting the fraction with the highest essential oil content. The milling of the less friable fractions for hydrodistillation does not increase oil yield, and actually decreases the relative purity of the product with reference to its anethole content. The oil yield from hydrodistillation is positively affected by the use of smaller particles $(<425$ $\mu \mathrm{m})$, high particle ratio to water $(16 \%)$, and longer hydrodistillation times. However, anethole purity is higher after the first moments of hydrodistillation (60 min, $10.2 \%$ oil on a dry basis, with $96.6 \%$ TA content in the EO). Therefore, collecting the early fraction is a method for selectively producing trans-anethole. The response surface methodology to determine the ideal condition of hydrodistillation of ground star anise gave an equation that is a function of granulometry and time, as well as their interaction. The refractive index confirms the vegetable oil type, but only masscoupled chromatography was able to characterize its composition.

\section{ACKNOWLEDGEMENTS}

The authors are grateful to CNPq, CAPES for the scholarship provided (grant number: 1551238), as well as to the Graduate Program in Food Engineering (Federal University of Paraná, Curitiba, Brazil). They would also like to thank the Chromatography Group and Microextraction Techniques (CroMe) and the Applied Chemistry Research Center (CEPESQ), both from Federal University of Paraná, for their technical support throughout the project.

\section{NOMENCLATURE}

$\mathrm{EO}$

Star anise (Illicium verum Hook) essential oil

G (i)

GC-MS

Grinding tests for star anise fruit

HD (i)

Gas Chromatography-Mass

Spectrometry

Hydrodistillation condition from fractional factorial design

M (i) Star anise fruit different millings

R Retained fraction (\%) for different grinding time conditions
TA

TGA

$\mathrm{Y}_{\mathrm{DB}}$

Trans-anethole

Thermogravimetric analysis

Tield on a dry basis ( $\mathrm{Y}_{\mathrm{DB}}$, in $\mathrm{g} \mathrm{EO} /$

100 g dry matter)

\section{REFERENCES}

AOAC - Association of Official Analytical Chemists, Official methods of analysis of AOAC international (AOAC). (W. HORWITZ, Ed.) (2v. 17h ed). Gaithersburg: Association of Official Analytical Chemists, INC. (2000).

Asif, M., Yehya, A. H. S., Al-Mansoub, M. A., Revadigar, V., Ezzat, M. O., Ahamed, M. B. K., Oon, C.E., Murugaiyah, V., Abdul Majid, A. S., Abdul Majid, A. M. S. Anticancer attributes of Illicium verum essential oils against colon cancer. South African Journal of Botany, 103, 156-161 (2016). http://doi.org/10.1016/j.sajb.2015.08.017

Bhadra, S., Mukherjee, P. K., Kumar, N. S., Bandyopadhyay, A. Anticholinesterase activity of standardized extract of Illicium verum Hook. f. fruits. Fitoterapia, 82, 342-346 (2011). http://doi. org/10.1016/j.fitote.2010.11.003

Cai, M., Luo, Y., Chen, J., Liang, H., Sun, P. Optimization and comparison of ultrasound-assisted extraction and microwave-assisted extraction of shikimic acid from Chinese star anise. Separation and Purification Technology, 133, 375-379 (2014). http://doi.org/10.1016/j.seppur.2014.06.064

Chempakam, B., Balaji, S. (2008). Star Anise. In Parthasarathy, V. A.,. Chempakam, B, Zacharia, T. J. (Eds.), Chemistry of Spices (pp. 319-330). CAB International. http://doi. org/10.1533/9780857095688.487

Chouksey, D., Upmanyu, N., Pawar, R. S. Central nervous system activity of Illicium verum fruit extracts. Asian Pacific Journal of Tropical Medicine, 6, 869-875 (2013). http://doi.org/10.1016/S19957645(13)60155-8

Damodaran, S., Parkin, K., Fennema, O. R., Fennema's food chemistry (4th ed.). CRC Press/Taylor \& Francis (2008).

Garber, M., Herrlinger, R., Ciesielslsi, L. F. Production of anethole from sulfate turpentine residues. USA (1962)

Herrera, K. C. Intoxicación por anís de estrella. Acta Pediátrica Costarricense, 21, 60-61. (2009).

Howes, M.-J. R., Kite, G. C., Simmonds, M. S. J. Distinguishing Chinese star anise from Japanese star anise using thermal desorption - Gas chromatography - Mass spectrometry. Journal of Agricultural and Food Chemistry, 57, 5783-5789 (2009). http://doi.org/10.1021/jf9009153

Li, G., Sun, Z., Xia, L., Shi, J., Liu, Y., Suo, Y., You, J. Supercritical $\mathrm{CO}_{2}$ oil extraction from Chinese star anise seed and simultaneous compositional 
analysis using HPLC by fluorescence detection and online atmospheric CI-MS identification. Journal of the Science of Food and Agriculture, 90, 19051913 (2010). http://doi.org/10.1002/jsfa.4031

PubChem. (2005). Trans-anethole. Retrieved January 17, 2017, from https://pubchem.ncbi.nlm.nih.gov/ compound/trans?Anethole\#section=Top

Shreve, B., Thiex, N., Wolf, M. (2006). NFTA Method 2.1.4 - Dry Matter by Oven Drying for $3 \mathrm{hr}$ at $105^{\circ} \mathrm{C}$. Retrieved May 15, 2017, from http://www.foragetesting.org/files/ NFTAReferenceMethodDM-09-18-06.pdf

Tapia, M. S., Alzamora, S. M., Chirife, J. Effects of Water Activity (aw) on Microbial Stability: As a Hurdle in Food Preservation, in Water Activity in Foods: Fundamentals and Applications (eds G. V. Barbosa-Cánovas, A. J. Fontana, S. J. Schmidt and T. P. Labuza). Oxford, UK: Blackwell Publishing Ltd. (2007). http://doi.org/https://doi. org/10.1002/9780470376454.ch10

Tuan, D. Q., Ilangantileket, S. G. Liquid $\mathrm{CO}_{2}$ extraction of essential oil from Star anise fruits (Illicium verum H.). Journal of Food Engineering, 31, 4757 (1997). http://doi.org/http://dx.doi.org/10.1016/ S0260-8774(96)00030-1
Wang, G. W., Hu, W. T., Huang, B. K., Qin, L. P. Illicium verum: A review on its botany, traditional use, chemistry and pharmacology. Journal of Ethnopharmacology, 136, 10-20 (2011). http://doi. org/10.1016/j.jep.2011.04.051

Wang, Q., Jiang, L., Wen, Q., Effect of three extraction methods on the volatile component of Illicium verum Hook. f. analized by GC-MS. Wuhan University Journal of Natural Sciences, 12, 529534 (2007). http://doi.org/10.1007/s11859-0060080-7

WHO. Quality control methods for herbal materials. World Health Organization (2011).

Wong, Y. C., Lee, P. P., Nurdiyana, W. A. W. Extraction and antioxidative activity of essential oil from star anise (Illicium verum). Oriental Journal of Chemistry, 30, 1159-1171 (2014). http://doi. org/10.13005/ojc/300329

Zhai, Y., Sun, S., Wang, Z., Cheng, J., Sun, Y., Wang, L., Zhang, Y., Zhang, H., Yu, A. Microwave extraction of essential oils from dried fruits of Illicium verum Hook. f. and Cuminum cyminum L. using ionic liquid as the microwave absorption medium. Journal of Separation Science, 32, 3544-3549 (2009). http://doi.org/10.1002/jssc.200910204 